\title{
Plínio Sussekind Rocha: um mestre "ekcêntrico"**
}

Antonio Luciano Leite Videira

Recebido em 01/09/2017

Aceito em 02/09/2017

Para citar este artigo:
O excêntrico deve aqui ser entendido no seu duplo significado de alguém que se situa duplamente fora do centro e fora do uso geral.
Há, porém, uma coisa que talvez seja indubitável: ele é um homem invulgar, até excêntrico. Ora, um excêntrico, na maioria dos casos, é um caso particular e isolado. Não é verdade?

Dostoiévski

A Universidade acolhe, normalmente, duas classes distintas de acadêmicos, a primeira das quais - e é, de fato, a classe reconhecidamente tida e considerada como "primeira" - é a dos Investigadores; a segunda - e é, de fato, a classe assumidamente tida e considerada como "segunda" - é a dos Professores. Falso!, bradarão logo os poderes dominantes na Academia, o que há é a classe dos Investigadores-Professores ou dos Professores-Investigadores e a daqueles que, inaptos para a Pesquisa, limitam-se a dar aulas. (Só que, quanto a mim, encontrar verdadeiros Professores-Investigadores, isto é, sujeitos igualmente dotados e capacitados para ambas as vertentes da atividade universitária, é tão raro que raras seriam as instituições capazes de compor os seus quadros unicamente com eles.)

A grande maioria dos investigadores - dirão essas autorizadas (e autoritárias) vozes - está plenamente vocacionada e capacitada para se dedicar ao ensino de qualidade. Ora, a realidade é cada uma das vertentes Ensino/Pesquisa, desde que com a desejada qualidade, são fortemente exigentes quanto aos respectivos investimentos psicológico e temporal: preparar e dar aulas, disponibilizar os sumários; preparar e dar testes, corrigi-los e lançar as respectivas notas, atender alunos, e por aí fora. Por sua vez, a dedicação à pesquisa exige largos períodos de concentrada reflexão, acompanhada da execução de algoritmos e ou de experimentos, uns e outros cada vez mais elaborados. 
Ademais, dadas as notórias especificidades de cada uma dessas duas atividades, Ensino e Pesquisa, não é propriamente comum encontrar-se quem possua a mesma propensão psicológica para dedicar-se a ambas: ou se tem naturalmente vocação clara para uma ou para outra, mas não para ambas as vertentes da atividade acadêmica. A prática corrente para a grande maioria é, pois, a de se dedicar prioritariamente a uma ou a outra das duas. Quem se vê compelido a desempenhar ambos os papéis de Investigador e de Professor em simultâneo optará quase que inevitavelmente por menorizar uma delas em detrimento da outra.

O que há, pois, efetivamente, são investigadores, por via de regra especialistas numa área estrita (e comumente estreita) do saber, sobre a qual, diligente e empenhadamente, publicam o maior número possível de artigos, ensaios, monografias, resenhas e livros, todos eles quase que invariavelmente de interesse praticamente exclusivo de um grupo restrito de almas gêmeas com interesses comuns. Pletora essa de publicações que, a não ser pelas escassíssimas exceções de praxe, não deixa rasto duradouro, servindo sobremaneira para compor os curricula dos respetivos autores. Autores esses que, por essa via da publicação incessante, se vão naturalmente guindando às posições cimeiras da Academia, precisamente aquelas que, automaticamente, lhes conferem o direito de estabelecer e determinar os exclusivos critérios de acreditação acadêmica. Contribuindo de maneira imprescindível para a imensamente lucrativa indústria da publicação acadêmica (corporação inexcedivelmente exímia, ela própria, no estabelecimento e na imposição das regras, das normas e dos critérios determinantes da excelência científica) constituem com ela uma aliança de interesses recíprocos e mútuos proveitos. São estes, os investigadores, os únicos, portanto, que - no enquadramento do paradigma oriundo dos Estados Unidos, preponderante a partir do final da Segunda Guerra Mundial - efetivamente contam; os únicos que verdadeiramente importam. É esta a (auto) proclamada classe primeira.

Depois, vêm os segundos - os Professores - aqueles com maior pendor para o Ensino e, consequentemente, maior interesse pelo Aluno, entendido este em toda a sua diversidade espectral; ou seja, o professor, por definição impositiva, impõe-se a si próprio dedicar-se a todos os seus alunos, não se interessando apenas por aqueles percebidos como os mais aptos. Publicando, usualmente, bastante menos que os Investigadores, os Professores encontram-se, por isso mesmo, liminarmente subalternizados na instituição acadêmica, avaliados, frequentemente, como quase que inteiramente dispensáveis, dado que as suas funções podem, com proveito, ser desempenhadas pelos Investigadores. (O que é, isso sim, inteiramente falso.)

E chegamos, então, ao justo ponto por onde eu, efetivamente, desejo começar: é uma antiga e firme conviç̧ão minha que a Universidade - precisamente para poder fazer jus a considerar-se (e a ser considerada) como tal - deve valorizar, sem qualquer distinção, ambas as categorias de seus colaboradores, desde que estes, claro está, sejam provadamente capazes, seja numa ou outra (ou mesmo em ambas) das duas valências referidas, ambas elementos basilares estruturais da verdadeira Universidade. Não se trata, por conseguinte, de opor duas categorias antagônicas como para o pitagórico Empédocles, que estipulava um Cosmos regido pelos princípios da amizade (Philotes), o bom Eros, e da discórdia (Neikos), o mau Eros.

E o que dizer, então, da cada vez mais rara subespécie excêntrica - também usualmente marginalizada e subvalorizada -, daqueles cujos interesses não incidem sobre uma área específica e bem demarcada do saber, mas que se "dispersam" por domínios que poderão ser tão díspares como, digamos - para nos aproximarmos da nossa figura central -, a Mecânica Clássica e ... o Cinema? Estes "ex-cêntricos" excêntricos, dadas as peculiaridades dos seus interesses, não produzem, via de regra, obra original de monta, devidamente publicitada em plataformas qualificadas como de referência, em quantidade (não falemos da qualidade...) que possa ser admitida como necessária e suficiente para o imprescindível reconhecimento, pelos já referidos poderes dominantes na Academia. (Poderes esses, claro está, quase que invariavelmente despossuídos das classificações exigidas para aferir os putativos méritos e relevância acadêmica de alguém que se ocupe de assuntos que, no seu conjunto, não conjuguem da ortodoxia hegemônica.) Ou seja, e como propõe George Steiner, "a cultura é, provavelmente, um talento muito ambíguo."

E se - situação imperdoável! - o comportamento de alguém incluído nesta última categoria traduzir-se num tranquilo distanciamento e numa indisfarçável indiferença face ao padrão predominante? Pois bem: é justamente aqui, nesta última categoria, que vamos encontrar o personagem de que desejamos ocupar-nos. 
No já longínquo ano de 1955, das quarenta vagas atribuídas ao curso de Física da Faculdade Nacional de Filosofia (F. N. Fi.), da então denominada Universidade do Brasil, no Rio de Janeiro, então Capital Federal, apenas catorze foram preenchidas, reduzido contingente esse, que, entretanto, logo se viu reduzido a três indivíduos, que, mais do que meros colegas, cedo se fizeram amigos próximos para o resto das suas vidas: Jorge André Swieca, Nicim Zagury e eu. Eu que, por razões que ficarão claras no que se segue, irei debruçarme - mesmo que muito perfuntoricamente -, pelo primeiro dos acima nomeados.

A primeira impressão que tive do Jorge André, ao deparar-me com ele no curso pré-vestibular ministrado por alguns dos nosso futuros professores no ano anterior à nossa admissão foi a sua aparência extremamente jovem (contava ele então apenas dezessete anos). A mim, do alto dos meus "maduros" dezenove anos não me pareceu apropriado que se admitissem "criançolas" como aquela em ambientes de tanta exigência como se antecipava aquilo com que teríamos de nos defrontar. Fica, pois, aqui plasmada a 'perfeita justeza' daquele meu primeiro juízo sobre aquele que viria a posicionar-se, indisputadamente, como um dos mais insignes exemplares de toda a Física brasileira (e isso até hoje).

Prontamente, porém, tive a oportunidade para defrontar-me com a absoluta excecionalidade daquela "criança", logo no nosso primeiro ano, ao começar a estudar com o André em casa dos seus pais na Vieira Souto as abstrusas dificuldades da Álgebra Moderna. Recém-emersos da trivialidade da Matemática a que, até então, havíamos sido expostos, o nosso enfrentamento com as cadeiras de Análise Matemática e Álgebra Moderna fez com que, de início, até irmos tomando pé, sentíssemo-nos bastante desnorteados. Anote-se que, por aquela altura, os três primeiros anos de ambos os cursos de Física e Matemática cumpriam estritamente o mesmo currículo no que dizia respeito à Matemática, e que, fato altamente relevante, o grosso (se não mesmo a totalidade) dos nossos docentes daquela área eram adeptos ferrenhos da abstracção bourbakista. O que, entre outras consequências, como a de afastar para longe dos exigentes recintos da F.N.Fi. os menos capazes de lidar com toda aquela rarefação, fez com que, durante aqueles três anos, nunca se haja calculado uma integral ou resolvido uma equação diferencial (o interesse matemático esgotava-se na demonstração de requintados teoremas, apresentados, por vezes, em versões com um número diferente de hipóteses ou da eventual existência de uma solução da respetiva equação). Para aprendermos a calcular essas banalidades próprias de engenheiros fomos, André e eu, por sugestão dele, estudar pelo Courant.

Passaram-se longas décadas até eu chegar a admitir convictamente que - muitíssimo mais importante do que termos sido treinados na resolução mais ou menos rotineira de problemas específicos de Matemática, solúveis com maior ou menor dificuldade técnica - foi a nossa exposição a todo um processo que nos ensinou a pensar! E isso (basta pensar um pouco) é o que realmente conta! Obrigado, pois, muito obrigado, incompreendidos bourbakistas.

Cumpridos por André, Nicim e eu os nossos dois primeiros anos, ingressámos no temeroso terceiro ano, tido como a etapa decisiva que iria, desde logo, sinalizar, se não mesmo predeterminar, aqueles que poderiam vir a aspirar a seguir uma carreira profissional em Física. Era no terceiro e penúltimo ano que se dava um notório aumento na dificuldade conceitual e formal das cadeiras de Física: aparecia o Eletromagnetismo com o Tiomno (assessorado pela Sarah), a Mecânica Quântica com o Leite e, sobretudo, a temível barreira da Mecânica Analítica, feudo exclusivo do Plínio, reconhecidamente o obstáculo mais desafiador de todos os nossos exigentes cursos em Física ou Matemática.

Plínio, aliás, não escondia, pelo contrário alardeava que ele se autopropusera assumir determinadamente o papel de árbitro que filtrava com rigor quem seria aprovado à primeira tentativa (fundamentalmente os poucos que poderiam vir a ambicionar seguir uma carreira acadêmica); quem só o conseguiria após duas ou mais tentativas; e, finalmente, aqueles que Plínio indefinidamente bloqueava.

Vem-me à lembrança um aluno de Matemática, uns anos anterior a nós, e com o qual, por algum motivo, Plínio decididamente embirrara. (Seria, talvez, por o tal aluno, que, reciprocamente, tomara Plínio como opositor declarado, assumir uma visão um tanto insuflada de si mesmo?) "O C. é burro!" declarava categoricamente o nosso professor de Mecânica Analítica (sem qualquer razão, quanto a mim). 
A propósito da indubitável aura de dificuldade que pesava sobre a Cadeira regida por Plínio recebi certo dia um telefonema de D. Renata, mãe do André, muito preocupada com o seu filho único, que lhe repetia insistentemente que ele não conseguiria passar na disciplina de um tal Professor Plínio. Bastante divertido com aquela inopinada informação, assegurei-lhe que quem, na realidade, andava um tanto intimidado com o filho dela era esse mesmo professor.

Com efeito, Plínio logo se apercebera da qualidade raríssima do André, uma das indicações que eu tivera disso mesmo (e que pusera Plínio numa posição algo defensiva face àquele aluno excepcional) tendo sido uma confidência do meu amigo, que verificara um pequeno erro na sua solução de um intrincado problema que o nosso professor lhe propusera num teste e que, apesar disso, este lhe atribuíra (como sempre) a nota máxima.

Não sei se seria prática corrente do Plínio, mas o que sei é que no nosso ano (1957), houve exames em que cada um de nós recebia questões individualizadas, sendo que, para o André, eram comumente selecionadas algumas que ele Plínio (como o próprio veio a confidenciar-me anos mais tarde) tinha dúvidas quanto às respectivas soluções. Lembro-me de exames de Mecânica Analítica sem limite de tempo para acabarem. (Vencia-nos pelo cansaço e pela fome, enquanto ele, divertidíssimo, comia sanduíches de mortadela e bebia guaraná que ele mandava o fiel Euclides trazer de um boteco próximo.) Aliás, para alguns (mas não todos) desses exames, Plínio permitia que levássemos todos os livros e apontamentos que pudéssemos considerar como nos sendo úteis, mas que, sabia ele, de nada nos serviriam.

Ao longo dos anos, Plínio convocava-me esporadicamente, fosse para acompanhá-lo à Cinemateca (de onde, infalivelmente, seguíamos para um dos dois únicos poisos que ele admitia frequentar: o bar Brasil (Adolfo até à Segunda Guerra) ou o restaurante Capela), ambos na Lapa; fosse para eu lhe arranjar um dentista, evidentemente, detentor de um conjunto de quase impossíveis valências, e ao qual, é claro que ele nunca chegaria a ir; fosse até para que eu lhe desencantasse um sítio para onde ele pudesse ir morar. Só que, tratando-se de Plínio, qualquer questão sua - retorcido problema de Mecânica, sutil apontamento cinematográfico, hipotético dentista ou a tal urgente habitação - vinha invariavelmente acompanhada por "condições de contorno" especialíssimas, que, na prática, faziam com que levá-la a bom termo fosse tarefa muitas vezes fadada a manter-se indefinidamente em suspensão. Assim, mesmo em face da premência em encontrar-se um teto para Plínio e a sua jovem Mirce, essa questão não poderia eximir-se a cumprir um inevitável e rigoroso caderno de encargos: ser barato, perto de um hospital e em zona frequentada pelas damas profissionais da noite. "Mas Professor" - Plínio, além de Shemberg e Beck, foram os únicos a quem eu nunca deixei de tratar assim -, "para quê a presença dessas senhoras?” e ele, logo com a resposta pronta: “Claro, Luciano, pois onde é que eu poderei encontrar café e cigarros durante toda a noite, se não nos sítios frequentados pela variada humanidade que convive com as ditas senhoras?" Elementar, não é mesmo? Daí que, quase tão elementarmente óbvio foi situar na velha Lapa a solução que acabou por ser o último (e modesto) abrigo de Mestre Plínio.

Passado pouco tempo do início das aulas de Mecânica Analítica (invariavelmente ministradas ao final da tarde, dado o tardio despertar do notívago regente da Cadeira), Mestre Plínio passou a convocar-nos ao André, ao Nicim e a mim para pequenas reuniões, nas quais ele dava-nos a ver alguns dos seu filmes de culto (só me recordo de filmes de Eisenstein), cuja joia cimeira era, só podia ser, a única cópia (em muito mau estado) então existente em todo o mundo do mítico, do incomparável, do inexcedível, do divino "Limite" do seu amigo Mário Peixoto.

E foi neles, nos seus domínios na F. N. Fi., que Plínio, sobretudo, segura e definitivamente nos cativou. Em sessões absolutamente fascinantes, nas quais, a espaços, Plínio, interrompendo a projeção, passava a discorrer sobre determinadas cenas do filme em questão com um tal poder encantatório, com uma tal profundidade de análise, com um tal conhecimento técnico, que nós, deslumbrados, éramos levados a "ver" aqueles filmes de um modo a que só acedíamos pela magia da sua intermediação. Felizes, ditosos aqueles poucos eleitos a quem Mestre Plínio com a sua erudição e o seu domínio soberbo da palavra assim privilegiava.

Mas não era apenas de Cinema que se tratava naqueles encontros. A certa altura, trouxe-nos um livro integrado nas comemorações do septuagésimo aniversário de Albert Einstein em 1949. Guiados por ele, passámos, então, nós os três, a expor alguns dos ensaios contidos naquela obra, tendo sido assim, por sua 
mão, que começámos a aprender a organizar o nosso discurso de forma a podermos expô-lo publicamente. Mais que não fosse, aquela sua iniciativa bastaria para singularizar Plínio como elemento fulcral naquela altura da nossa formação.

Plínio detinha um tipo de inteligência que eu classifico como indutora de uma espécie específica de síndrome paralisante, que incide sobre indivíduos que, indubitavelmente superiores intelectualmente e, frequentemente, possuidores de uma vasta erudição, não produzem obra consentânea com essas suas naturais competências. O que não significa que não se dediquem seriamente ao estudo de determinados tópicos, como, no caso de Plínio, por exemplo, o seu demorado interesse pela questão do Tempo. Simplesmente, por um certo pudor, por uma natural reserva elitista, por um extremado sentido autocrítico, raramente se dispõem a dar a conhecer os frutos do seu pensamento.

Em oposição a estes, quantos, muito menos dotados, não rompem com sucesso as suas naturais deficiências e, movidos por uma óbvia ambição, por uma inflexível determinação, por uma enorme capacidade de trabalho, não atingem patamares de elevado reconhecimento interpares?

No caso de Plínio, a única obra sua que lhe conheci foi uma monografia datilografada sobre Mecânica Analítica, e isso mesmo porque ele havia sido compelido a torna-la pública, forçado que fora pelo já referido C., a submeter-se a um concurso para provimento da Cátedra da Cadeira que o nosso Mestre ocupara interinamente desde sempre. Concurso esse, porém, que, à boa maneira das normas próprias e correntes de certas instituições em certos países, nunca ter chegado ao seu termo. Entre divertidos e também algo irritados com o desplante de C., nós, os discípulos fieis, vimos naquela atitude tão-somente um inconsequente, descabido e, em última análise, irrelevante desafio, que apenas poderia servir para incomodar o seu antigo e declarado opositor.

Plínio atravessou, pois, toda a sua carreira universitária praticamente sem publicar fosse o que fosse e, no entanto, foi, seguramente, uma das figuras mais marcantes e mais determinantes de todo o panorama acadêmico do Rio de Janeiro do seu tempo.

A propósito da evidente relutância plínica em plasmar o seu pensamento em letra de forma recordo uma pequena reunião em casa de Sarah, alguns anos após a morte dele, em que quatro dos seus assumidos admiradores, munidos de um gravador e de uma garrafa de whisky, se haviam proposto produzir uma pequena publicação conjunta, que reunisse algumas das nossas memórias de Mestre Plínio. Eu, desconfiado, achei por bem alertar os meus companheiros de que, de uma forma ou outra, Plínio, dada a sua visceral aversão a qualquer publicação que o envolvesse, encontraria meio de obstar os nossos bem-intencionados (para ele, porém, intempestivos) propósitos. Conscienciosamente esvaziada a nossa garrafa motriz, naturalmente desejámos ouvir o que ficara registado daquele intercâmbio de plínicas reminiscências. Só que - e como eu antecipara - nada, rigorosamente nada, ficara gravado; nem uma palavra sequer. Para mim, ficou claro, que Plínio, evidentemente presente (de alguma forma não muito evidente) impedira que a ingênua iniciativa daqueles seus amigos atingisse os seus objetivos.

Componente estrutural do carisma plínico eram, de uma parte, as suas birras de estimação e, de outra, a sua declarada antipatia por variadas personagens, umas e outras, claro está, ciosamente cultivadas por ele. Assim, entre as suas mais fundas e firmes embirrações sobressaía notoriamente o cinema falado, objeto esse, coisa essa, que ele soberanamente desconsiderava e desclassificava, como, a rigor, não devendo, sequer, ser tomado como cinema, pelo menos como ele o definia e entendia. Sucessão de diálogos de música, de ruído, o "cinema" sonoro não passaria de uma espécie de teatro filmado, com ênfase prioritária naquilo que se diz e como se diz. Portanto, para ele, injustificada intromissão, determinadamente contrária à essência do autêntico Cinema, o qual deveria exclusivamente ocupar-se da composição minuciosa e do rigoroso enquadramento de cada plano; da criação da justa cenografia e da correspondente iluminação de cada cena; da montagem definitiva da obra final.

Plínio e o Cinema... cigarro aceso entre os dedos, voz ofegante, a ditar imperiosamente: "Cinema" - e detinha-se para respirar e dar ênfase ao que se seguiria - "Cinema" - repetia - "é corte!" (E vem-me à memória a assombrosa cena da escadaria de "Couraçado Potemkin"...) 
Plínio e o Cinema ... quantas histórias únicas, quantos momentos irrepetíveis. Incluo aqui duas que adequadamente refletem a sua tão típica e permanente atitude de bem-disposta provocação. Certo dia convocou-me a acompanhá-lo à Cinemateca onde estava a ser exibido "Cenas de um Casamento" de von Stroheim. Ao entrarmos, Plínio começou por declarar que se deveria indefetivelmente procurar lugares no lado esquerdo da sala e a uma distância da tela que levasse em conta as dimensões da mesma. Indisputada, por óbvia, esta segunda condição, já quanto à primeira fiquei totalmente às escuras. À esquerda? Mas porquê à esquerda? E ele, como se aquela incondicional imposição fosse a coisa mais óbvia e mais evidente deste mundo, lá se dispôs a convencer-me, lançando, como primeira e formidável salva, o nome de Leibniz. Leibniz? Atônito com aquela absolutamente inusitada correlação entre tão eminente figura e a cadeira em que nos deveríamos sentar para assistir a um filme, confesso que perdi inteiramente contato com o seu discurso; discurso esse que, indubitavelmente, deverá ter deixado supinamente claro que apenas gente de poucas luzes e fraco entendimento (como era notoriamente o meu caso...) poderia pôr em causa uma tão evidente exigência, bem como a sua naturalíssima ligação com o pensamento do filósofo e matemático de Leipzig. Áh, grande Plínio!

À saída, acendendo o inevitável cigarro, atirou-me outra finíssima provocação: "E o espermacete, Luciano?" E, pronto, lá me encontrei eu, outra vez, sem perceber o que ele quereria dizer. Espermacete? Mas qual espermacete, por todos os ínclitos numes do panteão cinematográfico? O meu inevitável, e por ele antecipado embatucamento foi a deixa para que ele, deliciado, com a oportunidade por ele próprio engendrada me fizesse ver que eu pouco ou mesmo nada tivesse apreendido do que essencialmente importava na obra de Stroheim, cujo cerne, cujo fulcro se centrava clara e indisputadamente no plano que mostrava uma vela a derreter-se num pequeno e modesto castiçal. Ali - não na cera, nem mesmo na estearina, mas no espermacete - condensava-se, segundo Plínio, toda a intenção da mensagem pretendida e quem, desde logo não apreciasse essa fácil evidência ... Ficava a pairar no ar a evidente necessidade de alguém como ele para iluminar o pobre de mim, incapaz de, sozinho, aceder ao âmago daquilo que acabaramos de ver. Tudo isso, porém, com a sua soberba e aristocrática elegância intelectual que invariavelmente muito me divertia. E lá seguíamos então os dois, Mestre e discípulo, a pé, até à inevitável Lapa.

Plínio alimentava e acarinhava um seleto rol de figuras das quais guardava um higiênico distanciamento físico e intelectual. Aliás, com Plínio, era praticamente impossível alguém manter-se neutro: ou bem se apreciava o seu modo de ser, ou, simetricamente, se era quase que automaticamente repelido pela sua postura explicitamente elitista, pela sua recorrente ironia, pela implacabilidade do seu sempre definitivo julgamento, muitas vezes, além de corrosivo, monumentalmente excessivo (embora sempre na direção correta).

Em oposição expressa à orientação acadêmica "americana", particularmente personalizada naquela altura por Tiomno e Leite - os quais, por seu lado, não hesitavam em declarar a sua desaprovação e o seu antagonismo à linha de conduta defendida por aquela perigosa figura - Plínio contava com alguns poucos (mas bons) aliados, onde sobressaiam Schemberg na USP e Gross no Instituto de Tecnologia da Avenida Venezuela no Rio. Costa Ribeiro, que chegou a dar-nos aulas exta-curriculares, nas quais ele reproduzia experiências sobre o efeito piezoelétrico por ele descoberto, e também bastante isolado no panorama da ainda incipiente Física brasileira, navegava nitidamente à parte. Faleceu tragicamente, praticamente à minha frente, fulminado por um ataque cardíaco durante uma recepção no Clube Piraquê em homenagem a Yang, então de visita ao Rio, a convite do Jayme.

E porquê - poderão perguntar os dois ou três leitores desta pobre crônica dos plínicos tempos -, apodar Plínio de "perigoso" elemento, pelo menos no estrito sentido socrático? Desde logo, evidentemente, por ele - na visão pragmática daqueles doutorados por Princeton - poder desviar jovens com eventual potencial para a pesquisa em Física, deslumbrando-os e inutilizando-os com fátuos caminhos de improdutiva, estéril e inútil erudição.

Denunciado por E., um tristemente notório pilantra da F. N. Fi., Plínio frequentou durante alguns dias um dos calabouços mantidos pela Marinha de Guerra na Ilha das Cobras, no seguimento do Golpe Militar de 1964, por suspeita de ser sua a cópia de "Potemkin", exibida em sessão especial para subalternos da Armada, com o evidente intuito, segundo a acusação, de emular os subversivos antecedentes de 1905, envolvendo a esquadra imperial russa do Mar Negro, então fundeada em Odessa. 
Qual, efectivamente, seria a orientação política de Plínio? Francamente, não sei (nem nunca foi questão que me interessasse ou inquietasse). Embora seja-me difícil imaginá-lo como adepto de uma linha de Direita, não o vejo, igualmente, a aderir assumidamente a um posicionamento político estrito de Esquerda. Tal como eu sempre entendi Mestre Plínio, uma tal arregimentação nunca me pareceu compatível com o seu tão próprio, tão singular, modo de ser. Mas, insisto, não sei.

Nos últimos tempos de vida, Plínio viu-se confrontado com incômodas e agudas dificuldades financeiras. (Nada que, com penalizante periodicidade, não continue a afligir certos estratos da sociedade acadêmica brasileira, sistematicamente subalternizada e desconsiderada pelos diversos poderes constituídos.)

Dada a premência do quadro em questão, recorri a uma seletiva coleta envolvendo colegas do Rio e de São Paulo que pudessem ser sensíveis à frágil situação em que Plínio se encontrava. Devidamente munido de um cheque meu, no qual eu reunira todas as contribuições da comunidade por mim contatada, desloqueime à sua modesta morada e, muito embaraçado com tudo aquilo, fui incapaz de entregar-lho em mãos, depositando-o o mais discretamente possível em cima de um móvel. Plínio, como sempre, esteve à altura do momento. Sem sequer dirigir o olhar para aquele pedacito de papel, declarou serena mas firmemente que não poderia aceitar qualquer contribuição que incluísse os físicos irmãos paulistas Fulano e Beltrano, os quais, efetivamente, haviam prontamente e de bom grado acedido à minha solicitação. Apanhado de surpresa $\mathrm{e}$ totalmente ignorante quanto aos poderosos motivos por detrás daquela insólita recusa, retorqui com igual firmeza que aquele cheque estava assinado por mim e que, portanto, sendo eu o responsável primeiro e último por tudo aquilo, encararia a sua recusa como diretamente dirigida a mim. Plínio lá se conformou a ficar com o cheque, mantendo-se, porém, integralmente coerente com a sua muito própria maneira de ser: não faço, até hoje, a mínima ideia de como ele o terá conseguido, mas constou-me que arranjara meio de fazer com que as respetivas quantias fossem devolvidas a ambos os irmãos.

Poucos dias antes da sua morte fui, pela derradeira vez, ao seu encontro no hospital onde, inapelavelmente desenganado, aguardava, tranquila e senhorilmente, o fim que se anunciava iminente e do qual estava perfeitamente cônscio. Recebeu-me com a cordialidade de sempre, como se aquilo não passasse de mais um encontro nosso, em nada diferente de todos os outros. Propôs-me, então, um último - e como sempre - nada trivial desafio: que eu procurasse encontrar, fosse onde fosse (e onde é que poderia ser?) um projetor que pudesse fazer a devida justiça às peculiares dimensões dos fotogramas do FILME, de que ele fora o guardião cioso e ciumento da única cópia então existente. Escrevo assim, em maiúscula, para acentuar que, para Plínio, "Limite" superava tudo que se fizera (e que jamais poderia vir a ser feito) em Cinema.

Fingindo ignorar a minha evidente total incapacidade quanto à possibilidade de resolver com sucesso o que ele me solicitava, empenhou-se em sublinhar a urgência inadiável de tal empreendimento. Sabíamos ambos que tudo aquilo não passava de mais um dos seus jogos-desafios - o último -, mas que, servindo como delicado biombo para desviar da nossa presença a incômoda morte que se avizinhava, remetia-nos a ambos para o objeto que ocupara um papel tão decididamente central no espírito de Plínio. Com efeito, embora gerado pelo recluso da Ilha Grande, "Limite" foi, indisputadamente, uma criação de Plínio, que o distinguira e singularizara com uma peça cinematográfica cimeira a todas as demais. Para quem conviveu com Plínio não há qualquer resquício de dúvida que "Limite" foi, de fato, o magnum opus da sua vida.

Dado o seu interesse em Física ter-se substancialmente circunscrito à área da Mecânica Clássica e, mesmo aí, ele não se ter propriamente dedicado à pesquisa, Plínio não pode ser considerado rigorosamente como tendo sido um físico. O que, todavia, - face à inquestionável relevância do papel por ele desempenhado no cenário universitário do Rio de Janeiro do seu tempo - é inteiramente irrelevante. Com efeito, quem, além de Plínio, impressionou e marcou, de um modo tão próprio e tão indelével, tantos daqueles jovens que vieram, eles sim, a tornarem-se físicos profissionais? Quem, além de Plínio, influiu tão funda e tão duradouramente sobre todos aqueles (como este modestíssimo e manifestamente insuficiente escriba) que tiveram o privilégio ímpar de com ele privarem mais ou menos de perto? A resposta é pronta e fácil: Ninguém!

Obrigado por tudo e até sempre, Professor. 